\title{
OPTIMASI K-MEANS DENGAN PARTICLE SWARM OPTIMIZATION PADA PENGELOMPOKKAN DAERAH STUNTING
}

\author{
K-Means Optimization With Particle Swarm Optimization Algorithm to Determine \\ Cluster of Stunting Area
}

\author{
Harliana*1 $^{* 1}$ Raden Mohamad Herdian Bhakti ${ }^{2}$, Otong Saeful Bachri ${ }^{3}$, Fery Sofian Efendi ${ }^{4}$ \\ ${ }^{1}$ Program Studi Ilmu Komputer, Fakultas Eksakta, Universitas Nahdlatul Ulama Blitar, Indonesia \\ ${ }^{2,3}$ Program Studi Teknik Informatika, Fakultas Teknik, Universitas Muhadi Setiabudi Brebes, Indonesia \\ ${ }^{4}$ Program Studi Manajemen Informatika, Jurusan Teknologi Informasi, PSDKU Polinema Kediri, \\ Indonesia \\ e-mail:*1harliana.hifzhiya@ gmail.com, ${ }^{2}$ herdian.bhakti@umus.ac.id, \\ 3otongsaifulbahriumus@gmail.com, ${ }^{4}$ feri.sofian@gmail.com
}

\begin{abstract}
Abstrak
Stunting suatu kondisi balita yang memiliki tinggi badan lebih pendek dari usia normalnya. Berdasarkan data PSG Dinas Kesehatan Kabupaten Kediri di bulan februari 2018, tingkat prevelensi stunting di seluruh kecamatan Kabupaten Kediri sekitar 19,79\%. Melihat tingkat prevelensi yang tinggi tersebut, maka penelitian ini akan melakukan clustering terhadap 37 kecamatan yang ada di Kabupaten Kediri berdasarkan prosentasi tingkat stunting tertinggi sampai dengan terendah. Untuk mendapatkan hasil yang maksimal maka algoritma k-means yang digunakan akan dioptimasi dengan PSO. Berdasarkan hasil penelitian didapatkan bahwa rata-rata hasil nilai silhouette coefficient dan akurasi pada PSO $k$ means akan menghasilkan nilai yang lebih tinggi bila dibandingkan dengan k-means murni. Namun apabila dilihat dari waktu komputasinya maka k-means murni memiliki waktu yang lebih cepat bila dibandingkan dengan PSO k-means.
\end{abstract}

Kata kunci-stunting, optimasi, $k$-means, particle swarm intelligence

\begin{abstract}
Stunting is a condition of toddlers who have a height that is shorter than their average age. Based on PSG data from the Kediri District Health Office in February 2018, the stunting prevalence rate in all Kediri Districts was around 19.79\%. This study will group 37 sub-districts in Kediri Regency based on the highest to lowest stunting rates to reduce the prevalence rate. The k-means algorithm used will be optimized with PSO to get maximum results. Based on the results of the study, it is known that the average silhouette coefficient and accuracy on the PSO k-means will produce a higher value when compared to the pure k-means. However, when viewed from the computational time, pure k-means have a faster time when compared to PSO k-means
\end{abstract}

Keywords—stunting, optimization, $k$-means, particle swarm intelligence

\section{PENDAHULUAN}

Stunting merupakan suatu kondisi balita dengan tinggi badan yang lebih dari minus dua standar deviasi median dari standar pertumbuhan anak normal[1]. Dengan kata lain seorang balita dikatakan stunting ketika memiliki masalah pada gizinya sehingga mengakibatkan tubuh yang pendek dan sangat pendek berdasarkan usianya[2]. Berdasarkan data Pantauan Status Gizi (PSG) Dinas Kesehatan Kabupaten Kediri, tingkat prevelensi stunting di Jawa Timur pada tahun 2017 sekitar 26,7\% dengan Kabupaten Kediri sendiri memiliki tingkat prevelensi sebesar 19,79\% per Februari 2018. Untuk mencegah tingkat prevelensi yang lebih tinggi, maka pada tahun 2019 Kabupaten Kediri menjadi salah satu kabupaten dengan lokus stunting Jawa Timur

Informasi Artikel:

Submitted: September 2021, Accepted: Oktober 2021, Published: November 2021

ISSN: 2685-4902 (media online), Website: http://jurnal.umus.ac.id/index.php/intech 
oleh Kementrian Perencanaan Pembangunan Nasional dan Kepala Badan Pembangunan Nasional bersama 11 kota dan kabupaten lainnya yaitu Kabupaten Malang, Trenggalek, Probolinggo, Bondowoso, Nganjuk, Jember, Lamongan, Bangkalan, Sampang, Pamekasan, dan Sumenep.

Dari 37 kecamatan yang ada di Kabupaten Kediri, ternyata masih ada 16 kecamatan dengan prosentase stunting diatas $15 \%$ dimana 2 kecamatan tersebut adalah Kecamatan Kandangan dan Plemahan dengan tingkat prosentasi stunting sebesar 23,61\% dan 20,01\% atau setara dengan 323 dan 603 anak usia balita dari 1.368 dan 3.014 balita yang diperiksakan. Untuk menekan angka stunting ini, Dinas Kesehatan Kabupaten Kediri telah mencanangkan program Gerakan Peduli Keluarga (Garpu) dengan 9 kegiatan inovasi yaitu sarasehan atau rembuk stunting, balita cetar (ibu balita cerdas, sehat dan pintar), buku KIA lestari, lumbung pitutur paes manten, KPM (kader pembangunan manusia) di desa lokus, germas melalui pemanfaatan daun kelor, wirausahawan jamban, perubahan perilaku pada O-KPK (Organisasi Kader Penyuluh Kesehatan), dan kelas parenting yang akan mengedukasi keluarga yang memiliki anak PAUD. Melalui kegiatan sarasehan atau rembuk stunting yang telah dilakukan dari bulan Februari 2019 hingga Februari 2020, tingkat stunting yang terjadi di Desa Panjul Kecamatan Plosoklaten berhasil ditekan sekitar $1,38 \%$ atau setara mengalami penurunan dari 112 menjadi 81 balita yang mengalami stunting.

Berdasarkan hal tersebut, maka penelitian ini akan melakukan clustering terhadap desadesa di Kabupaten Kediri untuk melihat prosentasi tingkat stunting dari yang tertinggi sampai dengan yang terendah. Hal ini bertujuan untuk membantu Dinas Kesehatan Kabupaten Kediri dalam menerapkan skala prioritas penanganan yang tepat berdasarkan 9 kegiatan inovasi Gerakan Peduli Keluarga yang telah dicanangkan. Hasil dari clustering ini juga diharapkan dapat membantu pemerintah untuk menekan prevelensi stunting balita di tingkat nasional. Algoritma clustering yang akan dipakai dalam penelitian ini adalah K-means yang akan dioptimasi dengan PSO (Particle Swarm Optimization). PSO akan digunakan untuk mengoptimalkan nilai dari jarak antar cluster sehingga dapat menghasilkan pusat cluster baru yang lebih optimal [3]. Selain dengan PSO, penentuan nilai centroid yang optimal juga pernah dilakukan dengan menggunakan algoritma genetic[4][5][6] dan algoritma pillar [7]. Sedangkan untuk optimasi terhadap jumlah cluster dapat dilakukan dengan melakukan algoritma optimasi rule of thumn [8], pendekatan elbow [9], dan index davies bouldin [10].

\section{METODE PENELITIAN}

Metode penelitian yang dilakukan dalam penelitian ini adalah penelitian eksperimen dengan alur seperti gambar 1. Penelitian akan dimulai dengan proses observasi dan wawancara untuk mendapatkan dataset stunting di Dinas Kesehatan Kabupaten Kediri. Observasi dilakukan untuk mengetahui penyebab stunting yang terjadi, sedangkan wawancara dilakukan untuk mengetahui alur dan makna dari program garpu yang dicanangkan. Setelah data tentang stunting tersebut didapatkan maka langkah selanjutnya akan dilakukan preprocessing data. Preprocesing dilakukan untuk menghilangkan data pencilan / data yang outlier dari dataset. Untuk mendapatkan jumlah cluster optimal akan dihitung dengan menggunakan metode elbow melalui perhitungan Sum of Square Error (SSE) di persamaan (1) [11]

$S S E=\sum_{k=1}^{k} \sum_{x=1}\left|x_{i}-c_{k}\right|^{2}$ persamaan (1)

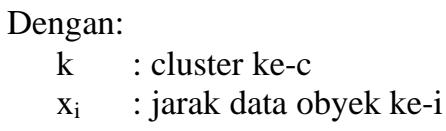


$\mathrm{c}_{\mathrm{k}} \quad$ : pusat cluster ke-i

Adapun tahapan yang dilakukan untuk melakukan PSO K-Means adalah sebagai berikut[12] :

a. Inisialisasi partikel yang berisi centroid setiap cluster dan kecepatan partikel melalui persamaan (2).

$$
V_{i}^{t+1}=\omega \cdot v_{1+}^{t} c_{1} x_{1} \cdot\left(p_{i}-x_{i}\right)+c_{2} \cdot r_{2} \cdot\left(p g_{i}-x_{i}\right)
$$

Dengan :
$\mathrm{V}_{\mathrm{i}} \quad$ : nilai kecepatan untuk partikel ke-i hingga ke-n.
$\mathrm{t} \quad$ : waktu iterasi.
$\omega \quad$ : nilai vector intertia.
$\mathrm{p}_{\mathrm{i}} \quad$ : posisi terbaik untuk setiap artikel.
$\mathrm{pg}_{\mathrm{i}} \quad$ : posisi terbaik untuk semua artikel.
$\mathrm{c}_{1}, \mathrm{c}_{2}$ : konstanta cognitive dan social.
$\mathrm{r}_{1}, \mathrm{r}_{2}$ : bilangan yang dibangkitkan secara acak antara 0-1

b. Tentukan partikel best dan global best awal.

c. Mulai iterasi berdasarkan sejumlah partikel dan lakukan tahapan berikut ini untuk setiap data vector:

i. Hitung dengan k-means.

ii. Tentukan cluster setiap vector dengan proses K-Means clustering

iii. Hitung nilai silhouette coefficient dengan persamaan (3).

$$
s(i)=\frac{b(i)-a(i)}{\max (a(i), b(i))}
$$

iv. Pengulangan akan berhenti ketika artikel terakhir.

v. Update centroid dengan menggunakan update kecepatan di persamaan (4) dan update partikel di persamaan (5).

$$
\begin{aligned}
& \omega=\left(\omega_{\max }-\omega_{\text {min }}\right) \frac{(\text { Iterasi }-t)}{\text { Iterasi }}+\omega_{\text {min }} \\
& x_{i}^{t+1}=x_{i}+V_{i}^{t+1}
\end{aligned}
$$

vi. Update partikel best dan global best

d. Iterasi berhenti ketika maksimum iterasi tercapai.

Rangkuman mengenai tahapan penelitian yang dilakukan terdapat pada Gambar 1.

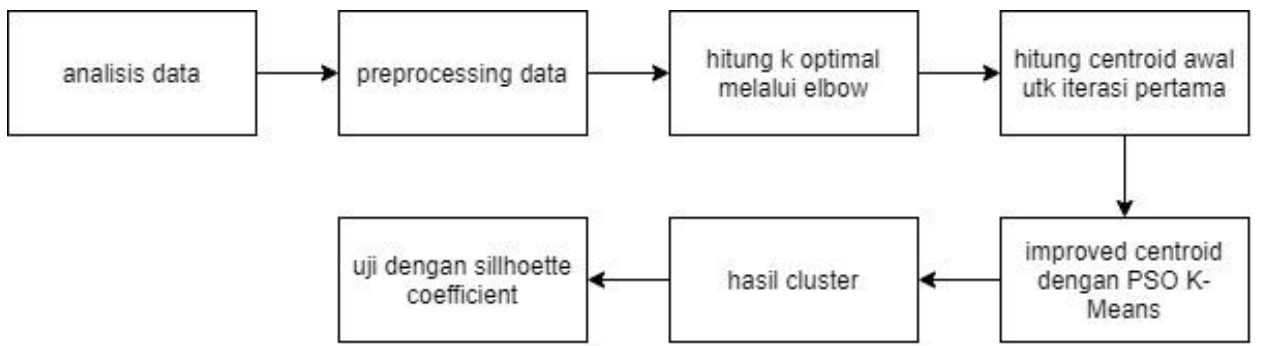

Gambar 1. Alur penelitian

\section{HASIL DAN PEMBAHASAN}

Optimasi K-Means Dengan Particle Swarm Optimization Pada Pengelompokkan Daerah Stunting (Harliana, Raden Mohamad Herdian Bhakti, Otong Saeful Bachri, Fery Sofian Efendi) 
Penelitian ini akan menggunakan dataset dari 37 kecamatan dan 37 puskesmas di Kabupaten Kediri. Untuk variabel yang digunakan dalam penelitian ini adalah:

a. Tinggi badan menurut umur, yang terbagi menjadi sangat pendek, pendek, normal, dan tinggi.

b. Berat badan menurut umur, yang terbagi menjadi berat badan sangat kurang, berat badan kurang, berat badan normal, dan resiko berat badan lebih.

c. Berat badan menurut tinggi badan yang terbagi menjadi gizi buruk (severely wasting, gizi buruk (wasting), gizi baik (normal), beresiko gizi lebih, gizi lebih, dan obesitas.

d. Supas (proyeksi balita).

e. Jumlah balita yang diperiksa.

f. Jumlah balita stunting (sangat pendek dan pendek).

g. Jumlah balita underweight (berat badan sangat kurang dan berat badan kurang).

h. Jumlah balita wasting (gizi buruk dan gizi kurang).

Gambar 2 adalah rangkuman rekap stunting yang terjadi di Kabupaten Kediri yang dikelompokkan berdasarkan kecamatan.

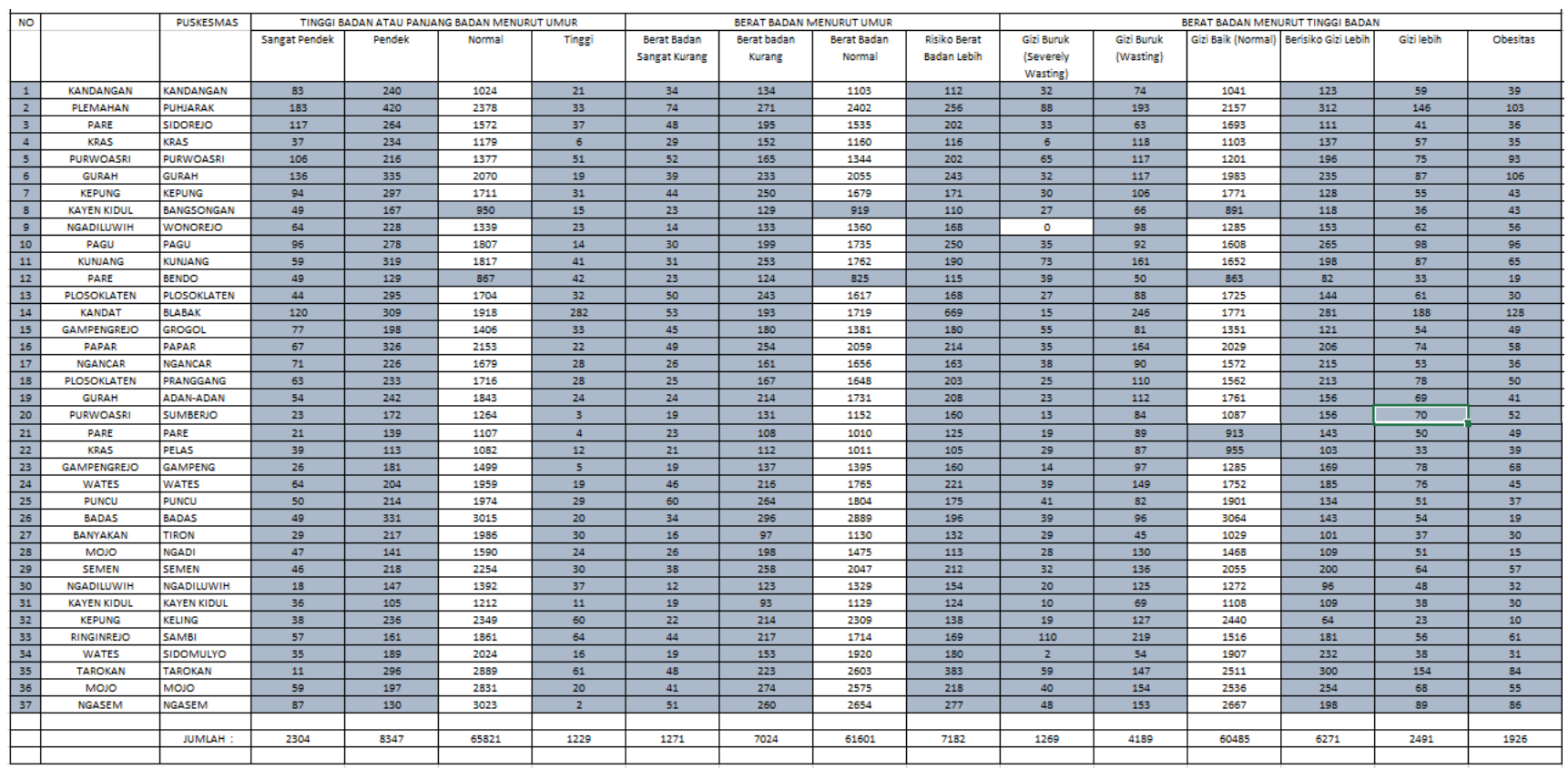

Gambar 2. Dataset stunting kecamatan

Pada tahapan preprocessing, peneliti memanfaatkan fitur replace missing value dari rapidminier. Hasilnya adalah tidak ada data yang missing, sehingga dataset yang akan diolah masih sama seperti dataset awal. Berdasarkan perhitungan dengan persamaan (3) maka jumlah cluster optimal yang akan digunakan adalah 2 cluster $(\mathrm{k}=2)$ dengan centroid awal di iterasi pertama adalah titik tengah dari dataset.

Sebelum melakukan perhitungan PSO maka akan dilakukan inisialisasi terlebih dahulu untuk mendapatkan nilai kecepatan masing-masing partikel seperti jumlah partikel $=13$, jumlah iterasi $=10$, cognitive $=1,5$ dan nilai $\mathrm{w}$. Selanjutnya akan dihitung nilai fitness berdasarkan persamaan (3), rangkuman mengenai nilai fitness yang dihasilkan terangkum pada Tabel 1.

Table 1. Nilai fitness yang dihasilkan

\begin{tabular}{cc}
\hline Partikel & Fitness \\
\hline 1 & 0,3210 \\
\hline
\end{tabular}




\begin{tabular}{cc}
\hline Partikel & Fitness \\
\hline 2 & 0,1156 \\
\hline 3 & 0,1423 \\
\hline 4 & 0,2109 \\
\hline 5 & 0,1190 \\
\hline$\ldots$ & $\ldots$ \\
\hline 28 & 0,1291 \\
\hline
\end{tabular}

Nilai fitness ini selanjutnya akan digunakan untuk mencari nilai pbest dan gbest dari fitness terbaik untuk setiap artikel $\left(\mathrm{p}_{\mathrm{i}}\right)$ dan fitness terbaik untuk semua artikel $\left(\mathrm{pg}_{\mathrm{i}}\right)$. Selanjutnya akan dihitung perubahan kecepatan melalui persamaan (2). Nilai w (vector inertia) pada persamaan (2) didapatkan melalui persamaan (4) dengan nilai konstanta cognitive dan social adalah 1 dan nilai $\mathrm{r}$ adalah bilangan random antara 0 dan 1 . Perhitungan untuk nilai $\mathrm{w}$ (vector inertia) berdasarkan persamaan (4) adalah:

$$
\begin{aligned}
& \omega=(0,6-0,2) * \frac{(10-1)}{10}+0,2 \\
& \omega=0,56
\end{aligned}
$$

Sehingga didapatkan nilai $\mathrm{v}_{\mathrm{i}}$ adalah:

$\mathrm{V}_{2,1}=0,56(0)+(1)(1) \cdot(25-30)+(1)(1) \cdot(25-30)$

$\mathrm{V}_{2,1}=-10$

berdasarkan hasil perhitungan diatas maka diketahui nilai kecepatan yang dihasilkan pada partikel 2 dimensi 1 adalah -10, perhitungan dan cara yang sama juga akan dilakukan untuk setiap partikel. Selanjutnya akan dilakukan perhitungan untuk perubahan posisi melalui persamaan (5). Dan proses PSO ini akan terus dilakukan sampai dengan maksimal iterasi dengan gbest position sebagai solusi yang diberikan. Tabel 2 adalah gbest partikel dari centroid yang dihasilkan.

Tabel 2. Representasi Partikel

\begin{tabular}{cc}
\hline Cluster & Global best position \\
\hline 1 & $-0,12845$ \\
2 & $-0,38032$ \\
\hline
\end{tabular}

\section{Pengujian}

Untuk mengetahui performa PSO terhadap K-Means maka akan dilakukan 3 jenis pengujian melalui 10 kali pengujian, yaitu:

a. Membandingkan hasil pengujian antara K-Means murni dan PSO K-Means berdasarkan rata-rata nilai silhouette coefficient yang dihasilkan oleh keduanya.

b. Membandingkan trata-rata nilai akurasi diantara keduanya.

c. Membandingkan rata-rata waktu komputasi.

Rangkuman hasil ketiga hasil pengujian tersebut terangkum pada Tabel 3.

Table 3. Hasil pengujian k-means dan PSO k-means

\begin{tabular}{cccc}
\hline Jenis Algoritma & $\begin{array}{c}\text { Rata-rata nilai Silhouette } \\
\text { coefficient }\end{array}$ & Rata-rata nilai akurasi & $\begin{array}{c}\text { Rata-rata waktu } \\
\text { komputasi }\end{array}$ \\
\hline k-means murni & 0,12337 & 0,6572 & 0,42 \\
\hline PSO k-means & 0,30731 & 0,8732 & 1,85 \\
\hline
\end{tabular}


Berdasarkan table 3 diketahui bahwa PSO k-means dapat membentuk model suatu cluster menjadi lebih baik bila dibandingkan dengan k-means murni, hal ini terlihat dari rata-rata nilai silhouette coefficient PSO k-means yang lebih tinggi bila dibandingkan dengan k-means murni. Untuk nilai rata-rata akurasi yang dihasilkan juga menunjukkan bahwa PSO k-means memiliki nilai akurasi yang lebih tinggi bila dibandingkan dengan k-means murni yaitu 87\%, namun apabila dilihat dari waktu komputasi yang dibutuhkan maka k-means murni lebih cepat bila dibandingkan dengan PSO k-means.

\section{KESIMPULAN}

Berdasarkan hasil penelitian yang telah didapatkan, dapat diketahui bahwa PSO kmeans mampu melakukan clustering yang lebih baik bila dibandingkan dengan k-means murni dalam mengelompokkan daerah stunting di Kabupaten Kediri. Hal ini terlihat dari nilai silhouette coefficient dan akurasi yang dihasilkan oleh PSO k-means lebih tinggi bila dibandingkan dengan k-means murni yaitu sekitar 0,30731 dan 87\%. Namun waktu yang diperlukan oleh PSO k-means dalam melakukan eksekusi cenderung lebih lama yaitu sekitar 1,85 detik bila dibandingkan k-means murni yang hanya sekitar 0,42 detik.

\section{DAFTAR PUSTAKA}

[1] A. D. Laksono and H. Megatsari, "Determinan Balita Stunting di Jawa Timur: Analisis Data Pemantauan Status Gizi 2017," Amerta Nutr., vol. 4, no. 2, p. 109, 2020, doi: 10.20473/amnt.v4i2.2020.109-115.

[2] C. Dewanti, V. Ratnasari, and T. Rumiati, "Pemodelan Faktor-faktor yang Memengaruhi Status Balita Stunting di Provinsi Jawa Timur Menggunakan Regresi Probit Biner," J. Sains Dan Seni Its, vol. 8, no. 2, 2019, [Online]. Available: http://ejurnal.its.ac.id/index.php/sains_seni/article/view/48519.

[3] D. Werdiningsih, D. Rahmawati, I. Cholissodin, and N. Santoso, "Optimasi K-Means untuk Pengelompokan Data Kinerja Akademik Dosen menggunakan Particle Swarm Optimization," J. Pengemb. Teknol. Inf. dan Ilmu Komput., vol. 3, no. 4, pp. 4102-4110, 2019.

[4] M. Mursalim, P. Purwanto, and M. A. Soeleman, "Penentuan Centroid Awal Pada Algoritma K-Means Dengan Dynamic Artificial Chromosomes Genetic Algorithm Untuk Tuberculosis Dataset," Techno.Com, vol. 20, no. 1, pp. 97-108, 2021, doi: 10.33633/tc.v20i1.4230.

[5] T. Taslim, D. Toresa, D. Jollyta, D. Suryani, and E. Sabna, "Optimasi K-Means dengan Algoritma Genetika untuk Target Pemanfaat Air Bersih Provinsi Riau," Indones. J. Comput. Sci., vol. 10, no. 1, 2021.

[6] D. A. Kuntjoro, B. D. Setiawan, and R. S. Perdana, "Algoritme Genetika Untuk Optimasi K-Means Clustering Dalam Pengelompokan Data Tsunami," J. Pengemb. Teknol. Inf. dan Ilmu Komput., vol. 2, no. 10, pp. 3865-3872, 2018, [Online]. Available: http://j-ptiik.ub.ac.id.

[7] A. Primandana, S. Adinugroho, and C. Dewi, "Optimasi Penentuan Centroid pada Algoritme K-Means Menggunakan Algoritme Pillar (Studi Kasus: Penyandang Masalah Kesejahteraan Sosial di Provinsi Jawa Timur)," J. Pengemb. Teknol. Inf. dan Ilmu Komput., vol. 3, no. 11, pp. 10678-10683, 2019, [Online]. Available: http://jptiik.ub.ac.id/index.php/j-ptiik/article/download/6748/3264.

[8] M. Nishom and M. Y. Fathoni, "Implementasi Pendekatan Rule-Of-Thumb untuk Optimasi Algoritma K-Means Clustering," J. Inform. J. Pengemb. IT, vol. 3, no. 2, pp. 237-241, 2018, doi: 10.30591/jpit.v3i2.909.

[9] A. Winarta and W. J. Kurniawan, "Optimasi Cluster K-Means Menggunakan Metode 
Elbow Pada Data Pengguna Narkoba Dengan Pemrograman Python,” JTIK (Jurnal Tek. Inform. ..., vol. 5, no. 1, 2021, [Online]. Available: https://jurnal.kaputama.ac.id/index.php/JTIK/article/view/466.

[10] E. Muningsih, I. Maryani, and V. R. Handayani, "Penerapan Metode K-Means dan Optimasi Jumlah Cluster dengan Index Davies Bouldin untuk Clustering Propinsi Berdasarkan Potensi Desa," Evolusi J. Sains dan Manaj., vol. 9, no. 1, pp. 95-100, 2021, doi: 10.31294/evolusi.v9i1.10428.

[11] D. A. I. C. Dewi and D. A. K. Pramita, "Analisis Perbandingan Metode Elbow dan Silhouette pada Algoritma Clustering K-Medoids dalam Pengelompokan Produksi Kerajinan Bali," Matrix J. Manaj. Teknol. dan Inform., vol. 9, no. 3, pp. 102-109, 2019, doi: 10.31940/matrix.v9i3.1662.

[12] I. Wahyuni, Y. A. Auliya, A. Rahmi, and W. F. Mahmudy, "Clustering nasabah bank berdasarkan tingkat likuiditas menggunakan hybrid particle swarm optimization," vol. 10, no. 2, pp. 24-33, 2016. 